1 Universidade de Brasília (UnB) - Brasília (DF) Brasil.

raelma.gesco@gmail.com

2 Universidade de Brasília (UnB) - Brasília (DF),

Brasil.

elizabethalvesjesus@gmail.com

3 Universidade de Brasília

(UnB) - Brasília (DF),

Brasil.

luciani.ricardi@gmail.com

4 Universidade de Brasília

(UnB) - Brasília (DF)

Brasil.

fatimasousa@unb.br

5 Universidade de Brasília (UnB) - Brasília (DF),

Brasil.

valeriamendonca@gmail.com

\section{O pensamento dos gestores municipais sobre a ouvidoria como um potencial instrumento de gestão participativa do SUS}

\author{
The thought of municipal managers about the ombudsman as a \\ potential tool of participatory management of the SUS
}

Raelma Paz Silva', Elizabeth Alves de Jesus ${ }^{2}$, Luciani Martins Ricardi3 ${ }^{\mathbf{3}}$, Maria Fátima de Sousa4, Ana Valéria Machado Mendonça ${ }^{5}$

RESUMO O estudo, de abordagem qualitativa, buscou, a partir do discurso de gestores municipais de saúde, identificar potencialidades à participação da comunidade na gestão do Sistema Único de Saúde (SUS), bem como compreender como esses gestores utilizam a ouvidoria para a tomada de decisão. Foram entrevistados 12 gestores, de quatro regiões do País, com posteriores transcrição e análise de discurso. Entendendo a participação como direito constitucional, as ouvidorias do SUS têm papel fundamental para a gestão, pois estimulam a participação individual do usuário e, em contrapartida, possibilitam ao gestor conhecer a opinião da população a respeito das ações e dos serviços de saúde ofertados no município.

PALAVRAS-CHAVE Defesa do paciente. Participação social. Gestão em saúde.

ABSTRACT The study, of qualitative approach, aimed, from the discourse of municipal health managers, to identify potential for the community participation in the management of the Brazilian Unified Health System (SUS), as well as understand how these managers use the ombudsman for decision-making. Were interviewed 12 managers, from four regions of the Country, with subsequents transcription and speech analysis. Understanding participation as constitutional right, the ombudsmen of the SUS have key role in the management, because they stimulate the individual participation of the user and, in counterpart, enable the manager to know the opinion of the population regarding the actions and health services offered in the municipality.

KEYWORDS Patient advocacy. Social participation. Health management. 


\section{Introdução}

A participação da comunidade na formulação, avaliação e fiscalização das políticas públicas no Brasil é uma conquista social que, ao longo dos anos, tem se ampliado em concepção e ferramentas que a viabilizem, de fato. A Constituição Federal (CF) de 1988, em seu artigo 37, além de trazer os princípios da legalidade, impessoalidade, moralidade, publicidade e eficiência para a administração pública direta e indireta de qualquer dos poderes da União, dos estados, do Distrito Federal e dos municípios, em seu parágrafo $3^{\circ}$, estabelece que

a lei disciplinará as formas de participação da comunidade na administração dos serviços públicos de maneira direta e indireta, com objetivo de fiscalizar, avaliar e contribuir para construção destes serviços. (BRASIL, 1988).

A partir de então, estabeleceu-se que o Estado deve ser responsável por instituir mecanismos que possibilitem a participação da comunidade na administração dos serviços públicos. Um desses mecanismos é a ouvidoria, que visa a, sobretudo, ser um canal de comunicação direta entre a administração dos serviços e a população a quem os serviços se destinam, possibilitando a participação individual.

Neste sentido, segundo a cartilha de implementação de unidades, a Ouvidoria Geral da União determina:

Ouvidoria pública deve ser compreendida como uma instituição que auxilia o cidadão em suas relações com o Estado. Deve atuar no processo de interlocução entre o cidadão e a Administração Pública, de modo que as manifestações decorrentes do exercício da cidadania provoquem contínua melhoria dos serviços públicos prestados. (BRASIL, 2012, P. 7).

Entretanto, as bases das ouvidorias vêm de longa data. O personagem que deu origem à figura do ouvidor público surgiu há mais de três séculos, na Suécia, quando o Rei Carlos XII ficou, durante 17 anos, longe de seu país em função das guerras. Foi então que, nesse período, criou-se o cargo do ombudsman, que significa, em português, 'representante'. Mas esse primeiro representante tinha como função supervisionar os trabalhadores do reino e, somente mais tarde, passou a ter um papel ampliado, com a responsabilidade de defender o cidadão ou o povo contra os excessos da burocracia do Estado (OMBUDSMAN SASKATCHEWAN, 2015). Aos poucos, essa função dentro do Estado foi se tornando a oportunidade de existir uma relação entre os cidadãos e a administração pública, mediada pelo ombudsman.

No Brasil, as primeiras experiências que denotam a presença de um ombudsman, personagem este que em nossa sociedade é conhecido como 'ouvidor', ocorreu ainda no período colonial, entre 1500 e 1822, e tinha como função o oposto do que é hoje, pois, nesse período, sua função era manter o rei de Portugal informado sobre o que ocorria na colônia. Esse cenário mudou após a independência, quando surge o ouvidor como 'juízo do povo', a quem a população poderia recorrer para relatar alguma injustiça e pedir providências (PEIXOTO; MARSIGLIA; MORRONE, 2013).

Entretanto, o marco para a discussão da ouvidoria como conhecemos hoje é o processo de redemocratização do País, nos anos 1980, com a implantação, primeiramente, de uma ouvidoria privada pela empresa Rhodia, em 1985, e, já no ano seguinte, a primeira ouvidoria pública, do município de Curitiba (PEIXOTO; MARSIGLIA; MORRONE, 2013). A partir de então, o País avançou muito nessa discussão, e começaram a surgir ouvidorias das políticas públicas implantadas na perspectiva de participação da comunidade por todo o País, nas três esferas: municipal, estadual e federal.

A ouvidoria não é apenas um instrumento ou mesmo um canal entre o cidadão e a 
Administração Pública. Trata-se de uma instituição de participação que, juntamente com os conselhos e as conferências, tem o dever de promover a interação equilibrada entre legalidade e legitimidade. (BRASIL, 2012, P. 7).

Outra conquista oriunda das lutas sociais iniciadas no período de ditadura militar e, depois, continuadas no processo de redemocratização foi o direito à saúde, também garantido constitucionalmente, no artigo 196 (BRASIL, 1988).

Para a efetivação desse direito, é instituído o Sistema Único de Saúde (SUS), que tem entre seus princípios e diretrizes a descentralização, o atendimento integral e a participação da comunidade, essenciais para a construção de um sistema de saúde democrático e que atenda às necessidades de sua população.

Mesmo já afirmada na CF em 1988, somente em 1990, com a Lei $\mathrm{n}^{\circ} 8.142 / 90$, foi regulamentada a participação da comunidade na gestão do SUS, momento em que se instituíram duas instâncias colegiadas de grande importância para a democracia participativa: as Conferências e os Conselhos de Saúde, sendo este último com funções deliberativas (BRASIL, 1990).

Conforme Rolim, Cruz e Sampaio (2013), essa pode ser considerada uma das maneiras mais avançadas de se efetivar a democracia, quando se reposiciona a relação entre Estado e sociedade na construção de políticas públicas menos horizontalizadas e mais próximas da realidade das pessoas que vivem as necessidades de saúde de cada comunidade.

Outro marco para a participação da comunidade na gestão do SUS foi a instituição, por meio do Decreto $\mathrm{n}^{\circ} 4.726$, de 9 de junho de 2003, da Secretaria de Gestão Estratégica e Participativa do Ministério da Saúde e, no âmbito dela, do Departamento de OuvidoriaGeral do SUS (BRASIL, 2003).

As ouvidorias são ferramentas estratégicas para a gestão do SUS, na medida em que possibilitam o diálogo entre a sociedade e a administração pública, contribuindo para a participação do cidadão na avaliação e fiscalização da qualidade dos serviços de saúde, com a proposta de subsidiar a tomada de decisão (BRASIL, 2009).

Assim como a atenção à saúde, as ouvidorias do SUS devem ser descentralizadas, de forma a serem implantadas e operacionalizadas também pelos estados e pelos municípios, para que o conjunto de ações e serviços de saúde possa ser avaliado pela população. Vale destacar que as ouvidorias do SUS precisam ir além de ser um espaço apenas para reclamação, devendo ser capazes de acolher demandas referentes a informações, sugestões, solicitações, denúncias, reclamações e elogios (BRASIL, 2014B).

[...] ouvidoria pública, ela se apresenta como um autêntico instrumento da democracia participativa, na medida em que transporta o cidadão comum para o âmbito da administração. Este através da ouvidoria, ganha voz ativa, na medida em que suas críticas, denúncias ou sugestões são acolhidas pela administração, contribuindo, dessarte, para a correção e o aprimoramento dos atos de governo. (LYRA, 2004, P. 4).

Ressalta-se, ainda, que nenhuma legislação atribui à ouvidoria algum poder deliberativo. Em suma, ela pode fazer: recomendações, sugerir, mediar, instruir, mas não exerce nenhum poder de decisão direto. Porém, além de sua relevância técnica, a ouvidoria pode ter um papel político na articulação entre as demandas da população e a gestão do SUS nas três esferas, favorecendo a efetivação da gestão estratégica e participativa no sistema.

Sendo assim, o presente trabalho tem o objetivo de compreender o pensamento dos gestores municipais de saúde sobre a ouvidoria como um potencial instrumento de gestão participativa do SUS, bem como 
a forma como a ouvidoria é utilizada para a tomada de decisão na gestão municipal.

\section{Métodos}

Trata-se de um estudo de abordagem qualitativa cujo desenho baseia-se na coleta de dados por meio de entrevistas com roteiro semiestruturado aplicado junto aos secretários municipais de saúde (gestores municipais). Foi considerado, ainda, como instrumento de coleta o diário de campo, composto pela observação do pesquisador, fundamental para compor a análise de contexto. $\mathrm{O}$ roteiro continha dez perguntas norteadoras, com a seguinte questão principal 'Como o gestor utiliza da ferramenta de ouvidoria como instrumento para subsidiar a tomada de decisão para a gestão?'. Foram questionados, também, sobre como as ferramentas de ouvidoria os auxiliam na resolução de alguma demanda de sua comunidade.

O critério de escolha dos participantes foi por conveniência, por serem municípios próximos a capital, que exigiam um tempo de deslocamento menor. Em contato prévio, realizado por telefone e/ou via e-mail, com a secretaria de saúde do município escolhido, foram agendadas as entrevistas nas datas indicadas. Os gestores municipais de saúde foram entrevistados de acordo com o município onde exercem sua gestão.

Foram visitados 13 municípios, contemplando as regiões Norte, Nordeste, Sul e Sudeste do País, no período entre julho de 2013 e janeiro de 2014. Realizaram-se 12 entrevistas, um dos gestores convidados não participou da amostra porque não se encontrava na secretaria de saúde na data e no horário marcados, e com impossibilidade de agendar outro momento para a entrevista.

Os dados foram submetidos a análise de discurso, forma de análise onde o objeto a ser estudado é o próprio discurso, fazendo análise da fala do sujeito. Como explica
Orlandi (1999), a análise de discurso visa a, a partir da própria interpretação, possibilitar a compreensão da história também sobre outra perspectiva. Foram estabelecidas duas categorias de análise: ouvidoria como mecanismo de participação da comunidade; e ouvidoria como instrumento de gestão.

Para melhor compreensão do objeto, foi realizada uma contextualização dos municípios visitados, que apresentam perfis diferentes e organização institucional complexa, na medida em que a população variava de 4 mil até 900 mil habitantes, o caso de uma capital com população equivalente à de uma metrópole, segundo a classificação do Atlas de Desenvolvimento Humano no Brasil (PNUD, 2015).

A pesquisa foi aprovada pelo Comitê de Ética e Pesquisa da Faculdade de Ciências da Saúde/UnB, sob o número 209/13, bem como foram respeitados todos os aspectos éticos que envolvem a pesquisa com seres humanos, em especial, a assinatura do Termo de Consentimento Livre e Esclarecido (TCLE) pelos participantes e a garantia do anonimato.

\section{Resultados e discussão}

Do total dos 12 gestores entrevistados, 7 eram do sexo feminino e 5 masculino, oriundos de variadas formações acadêmicas, entre elas: enfermeiro, médico, técnico de enfermagem, farmacêutico-sanitarista, professor, assistente social, biólogo, psicólogo e odontólogo.

A maior parte dos municípios apresentava uma rede de saúde bastante solidificada, no sentido de ter Equipes de Saúde da Família, hospitais de médio e grande portes, entre outros programas e iniciativas de proteção, promoção e recuperação da saúde. Todavia, em alguns dos municípios visitados, a rede de saúde era bastante reduzida, dado o porte do mesmo, com apenas um Centro de Saúde, um médico (colaborador do Programa Mais 
Médicos, iniciativa do Ministério da Saúde), uma enfermeira, uma técnica de enfermagem, Agentes Comunitários de Saúde (ACS) e uma atendente na recepção. Em um dos municípios, de 4 mil habitantes, a secretária de saúde exercia, também, a função de ouvidora.

Entre os municípios, 10 possuíam ouvidoria do SUS implantada e 2 estava em vias de implantação. Os municípios que já haviam implantado a ouvidoria se utilizavam das seguintes ferramentas para facilitar o acesso do usuário: caixas de sugestão, telefone, e-mail, site, cartas e ouvidoria itinerante, com a busca ativa na comunidade e realização de reuniões nos bairros.

E, nesse sentido, é importante destacar que nem todas as ouvidorias possuíam uma estrutura adequada para realizar o atendimento presencial do usuário, a exemplo das que contavam apenas com uma cadeira, mesa, telefone e um computador. Já no município específico em que a gestora exercia também a função de ouvidora, as demandas, solicitações e reclamações dos usuários eram feitas diretamente a ela, o que facilitava a resposta, apesar das dificuldades próprias de um município de pequeno porte.

Peixoto, Marsiglia e Morrone (2013, P. 792), em estudo realizado com funcionários e usuários de uma ouvidoria, identificaram um importante aspecto que dificulta o acesso e a participação efetiva dos usuários, ou seja, "[...] o receio que muitos tinham de se manifestar através da ouvidoria, com temor de represália por parte dos funcionários da instituição". Esses são desafios que expressam a problemática da participação da comunidade na fiscalização e na avaliação da política de saúde, os quais se ampliam nos municípios menores, pela reduzida oferta e proximidade do usuário, tornando-o refém da estrutura.

A análise de contexto permitiu classificar as iniciativas dos municípios em duas categorias: a) ferramentas tradicionais de recepção ao usuário (caixas de sugestão, telefone, e-mail, site, cartas); b) ferramentas de ouvidoria ativa: Fala Governo, atividade de ouvidoria itinerante, busca ativa na comunidade, reuniões nos bairros com a comunidade.

Figura 1. Ferramentas de acesso utilizadas pelas ouvidorias de 10 municípios brasileiros visitados. Brasil, 2014
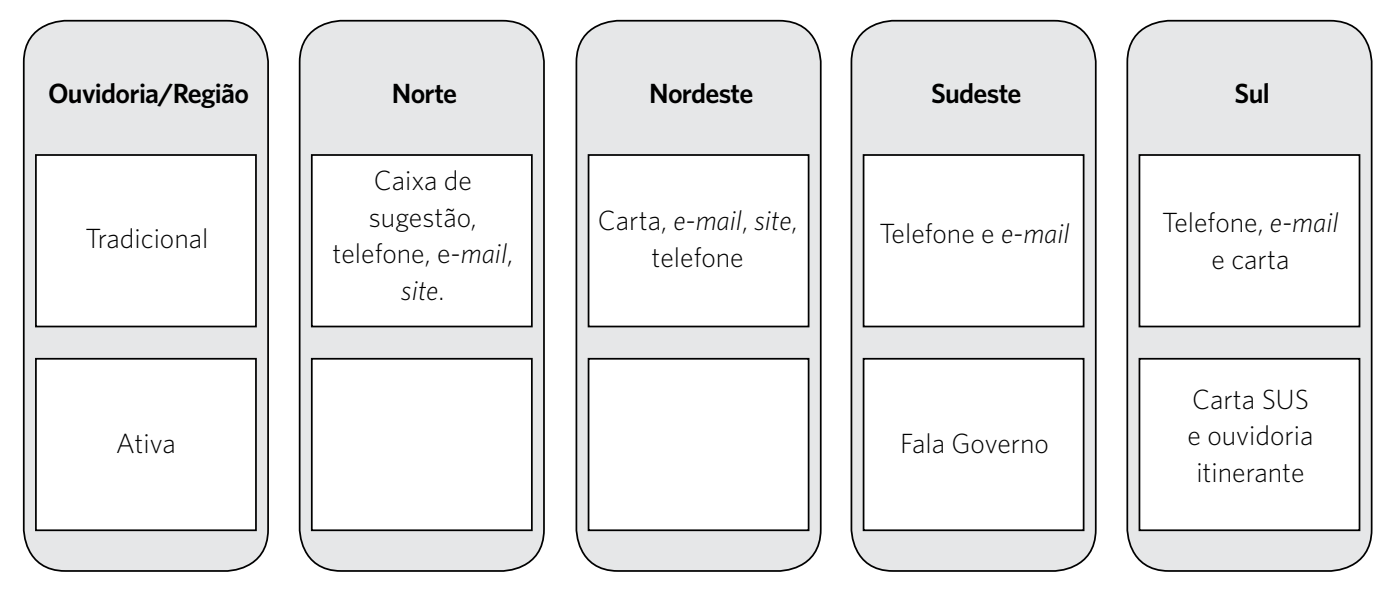

Fonte: Elaboração própria. 
Todos os municípios que possuem ouvidoria implantada utilizam as ferramentas tradicionais de ouvidoria: telefone, e-mail e carta. Foi possível observar, ainda, que nem todos eles disponibilizam telefone de ligação gratuita. Apenas um município em cada região mencionou a ligação gratuita, sendo que eram considerados de médio porte, com uma maior estrutura de saúde. Apenas dois municípios do Norte do País e um do Nordeste declararam usar caixinhas de sugestão. Quanto às ferramentas de ouvidoria ativa, dois municípios, um no Sul e o outro no Sudeste, fazem uso das ferramentas da Carta SUS e do Fala Governo.

A ouvidoria ativa se relaciona de modo mais próximo da comunidade, está incumbida de ir em busca das demandas da população, e não apenas esperar ser demandada. Um exemplo de uma atividade de ouvidoria ativa são as pesquisas de satisfação ou de nível de confiança ou aceitação dos usuários a respeito de determinada ação da instituição.

[...] essa ouvidoria é assim denominada pela natureza proativa de suas atividades: não apenas recebe demandas dos cidadãos e atua sobre elas, mas se incumbe de identificar e levantar informações junto aos cidadãos para subsidiar as decisões da alta direção do órgão/entidade quanto às melhorias e inovações que podem ser implementadas. (BRASIL, 2013B).

Das iniciativas de ouvidoria ativa identificadas nos municípios visitados, cabe destacar a estratégia do Fala Governo, que é um momento em que o secretário de saúde, juntamente com sua equipe de ouvidoria, dirige-se a unidade de saúde para a escuta da população e dos trabalhadores da saúde sobre suas necessidades, demandas, impressões a respeito dos serviços prestados.

Essa é uma iniciativa de um dos municípios visitados, instituída pelo secretário de saúde juntamente com a ouvidora, por entenderem que havia a necessidade de se aproximar da comunidade e buscar compreender suas necessidades. As escutas são realizadas nas unidades de saúde e os usuários têm a oportunidade de se manifestarem em relação ao atendimento, demandas ou sugestões. As questões levantadas podem subsidiar a gestão, tanto em relação a estrutura, como de readequação do quadro de trabalhadores e funcionamento da unidade em função da satisfação/insatisfação dos usuários.

Além disso, está instituída pelo Ministério da Saúde a Carta SUS, que é um mecanismo que possibilita a fiscalização dos serviços do SUS por parte da gestão e, com isso, o controle dos recursos públicos. A Carta é enviada a todos os usuários que foram internados ou realizaram algum procedimento ambulatorial de alta complexidade pelo SUS. A Carta SUS também faz pesquisa de satisfação do usuário quanto ao atendimento prestado no serviço de saúde, o que permite que o Ministério da Saúde tenha ciência da opinião dos usuários a respeito desses serviços (BRASIL, 2014C). Embora essa iniciativa já exista desde 2012 e já seja uma realidade em todo o País, apenas um dos gestores entrevistados mencionou a Carta SUS, quando questionado sobre as ferramentas utilizadas pela ouvidoria, possivelmente pelo fato de que a estratégia ainda é centralizada no âmbito federal.

A ouvidoria itinerante mencionada por um gestor se constitui na estratégia de escuta da comunidade em seu local de viver e produzir saúde. É o momento em que a gestão vai até os usuários - em especial, aqueles que vivem em condições de maior vulnerabilidade social - ouvir quais são suas necessidades, como estão percebendo os serviços de saúde, se estão sendo atendidos em suas necessidades mais específicas (BRASIL, 2014C).

Os dados evidenciam que a maioria das ouvidorias dos municípios visitados ainda se restringem às funções tradicionais de receber, registrar e encaminhar as demandas, sendo basicamente receptivas, com apenas 
duas iniciativas de ouvidoria proativa.

Com a implantação da ouvidoria no município, a gestão tem o desafio de fazer chegar aos usuários as ferramentas de que dispõe para atendê-los. Segundo o guia de implantação de ouvidorias desenvolvido pelo Ministério da Saúde (BRASIL, 2013A), é necessário disponibilizar a seguinte estrutura mínima: espaço físico determinado, localização de fácil acesso e visibilidade ao cidadão, acessibilidade (rampa e banheiros adaptados), equipamentos e mobiliário adequados para a realização do serviço, disponibilidade de linha telefônica e acesso à internet, espaço adequado para atendimento presencial, eventualmente com resguardo de sigilo.

Apenas um dos municípios com ouvidoria implantada não possuía um número telefônico para contato, embora nem todos os municípios tivessem um número para o qual o cidadão possa ligar gratuitamente. Essa é uma informação importante, porque nos remete ao grau de importância que a gestão atribui ao fato de democratizar e facilitar o acesso do usuário aos serviços oferecidos pela ouvidoria do SUS no município.

Via telefone gratuito. 156, gratuito, liga sem custo nenhum. Foi feita propaganda, foi distribuído panfleto. Está na rádio, propaganda na rádio também, nas unidades de saúde. Em todos os departamentos do município. É um número conhecido e está em todos os carros do município, a ouvidoria. 'Ligue para nós, faça a sua denúncia. Faça a sua informação'. E está estampado em todos os lugares, em todos os prédios públicos. (G.E.3).

Quando questionados a respeito das estratégias utilizadas para divulgação dos canais de acesso à ouvidoria do SUS, os gestores apontaram como mecanismo de divulgação os cartazes espalhados pela secretaria de saúde, nas unidades de saúde, sempre privilegiando espaços de maior visibilidade, com número telefônico, site, $e$-mail e endereço da ouvidoria. Além disso, os canais de mídias locais são instrumentos utilizados pela população para apresentar as deficiências do sistema. Os gestores percebem que esse canal amplia o alcance da fala dos usuários.

São diversas formas. Primeiro a gente mantém material informativo em todas as unidades, né? Em todos os serviços da Secretaria de Saúde, eles dispõem de informação com o número da ouvidoria, ele é bastante estimulado. Depois nós temos um jornal do município, que é o Diário Oficial, mas que tem uma farta publicação de matérias de coisas que a prefeitura fez etc. (G.E.9).

Destaca-se, ainda, que o fato de ter uma unidade de ouvidoria do SUS próxima aos serviços de atendimento à população facilita e agiliza o atendimento ao usuário, o que classificaram como atendimento 'olho no olho'.

Agora a maior parte das demandas é pessoalmente e logo depois do evento que realmente causou o incômodo para o usuário. Por exemplo, chegaram à unidade e não foram atendidos. $A$ unidade é próxima da ouvidoria. Eles já vêm imediatamente aqui. (G.E.10).

$\mathrm{O}$ atendimento acolhedor e humanizado prestado pelo ouvidor a esse usuário estabelece vínculo e torna possível o registro e o encaminhamento da demanda, como relata o gestor:

[...] nem sempre esse acesso à ouvidoria gera uma demanda que chega a ser registrada e encaminhada à outra instância. Com a orientação que o usuário recebeu da ouvidoria, às vezes, realmente o usuário se sente orientado e não registra a demanda, coisa que realmente essa orientação podia ter sido feita pelo funcionário no setor de onde ele veio. (G.E.8). 
Na perspectiva da relação entre a humanização e a ouvidoria, Carvalho, Santana e Santana (2009) apresentam uma experiência de profissional do campo da psicologia na função de ouvidor hospitalar, com os desafios da ouvidoria de ser, ao mesmo tempo, um canal de comunicação entre usuários, profissionais e gestores, com características de mediação. Os autores reforçam, ainda, que as ouvidorias possuem um potencial para serem microestruturas de controle social, que possibilitam a participação direta e individual do cidadão.

Convém observar que, em um dos municípios visitados, a ouvidoria da saúde foi a primeira experiência de ouvidoria do município, antes mesmo da prefeitura implantar uma ouvidoria geral do município, representando, com isso, que o SUS avança nas estratégias de participação da comunidade na gestão dos serviços.

\section{Ouvidoria como mecanismo de parti- cipação social}

A ouvidoria tem como finalidade possibilitar ao cidadão relacionar-se, diretamente, com o órgão ou a entidade pública para solicitar informações e apresentar sugestões, queixas, reclamações e denúncias relativas à prestação dos serviços públicos e/ou ao desempenho institucional, em geral (BRASIL, 2013B).

Ter a ouvidoria do SUS implantada em seu município, na opinião dos entrevistados, é a garantia de um canal de comunicação institucional entre a população e a gestão. Foi possível observar que os gestores entendem que a ouvidoria possibilita à gestão conhecer e reconhecer os problemas da comunidade e da prestação dos serviços de saúde.

A ouvidoria do SUS facilita a participação da comunidade na gestão das políticas públicas de saúde, cumprindo, assim, com o que preconiza a Constituição Federal. Auxilia a gestão na avaliação e monitoramento dos serviços prestados. (G.E.1).

Desde a conquista da redemocratização do País, o debate sobre administração pública democrática e participativa vem ganhando força em todas as instâncias de gestão. Com isso, a discussão de ouvidoria como mecanismo de participação da comunidade se apoia muito no fato de que a participação cidadã é garantida pela Constituição Federal de 1988 e que, portanto, deve representar uma forma de compartilhar as decisões políticas e administrativas do Estado.

Neste sentido, a ouvidoria é um espaço que promove cidadania quando reconhece a demanda, sugestão, elogio ou denúncia do cidadão e entende que essa fala tem de ser acolhida e levada às instâncias necessárias. Para que isso seja possível, depende, sobretudo, do amadurecimento da consciência cidadã e, ainda, da vinculação do gestor aos ideais de Estado democrático e de transparência na gestão pública.

É uma ferramenta que deve atuar sem formulação de juízo de valor na interlocução com a sociedade para consolidação de uma gestão participativa. A ouvidoria contribui para a ampliação de cidadania, propiciar relacionamento democrático e participativo entre governo e sociedade, permitindo identificar necessidades e distorções no âmbito dos Serviços de Saúde, como, também, buscar soluções para as manifestações apresentadas. (G.E.2).

Desvelaram-se, ainda, do discurso dos sujeitos pesquisados, sobre o papel da ouvidoria do SUS em seus municípios, as palavras que mais se repetiram nas entrevistas, conforme mostra o esquema abaixo. 
Figura 2. Palavras mais repetidas por gestores municipais de saúde quando questionados sobre o papel da ouvidoria. Brasil, 2014

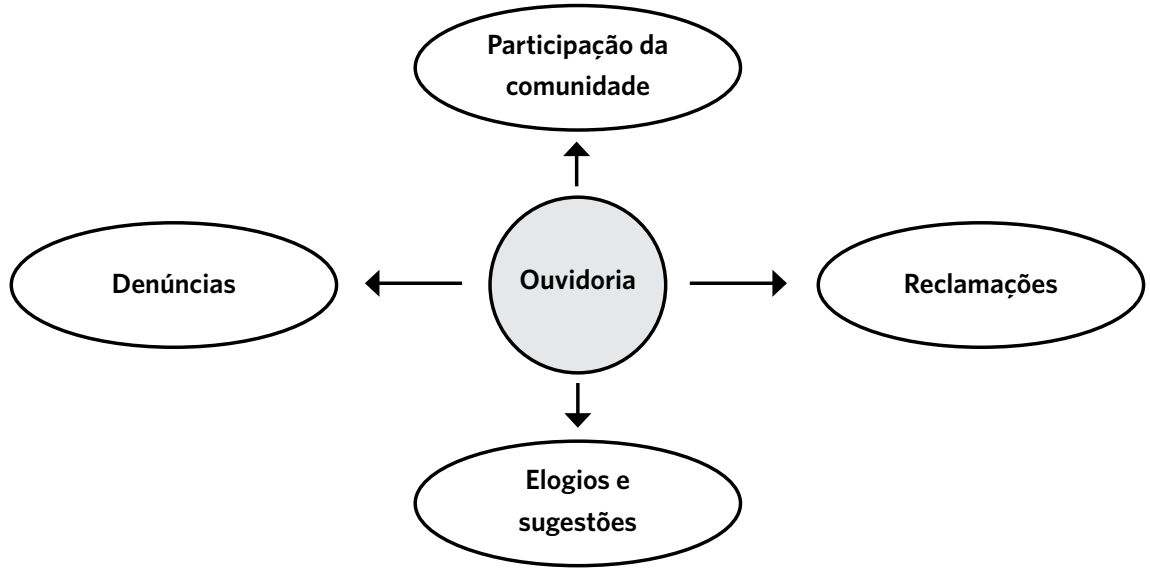

Fonte: Elaboração própria.

No discurso dos sujeitos, a participação social foi a palavra que teve maior repetição, como neste exemplo:

A ouvidoria, ela é como eu falei, ela serve como meio de comunicação e de participação social. Então, é através dela que a população consegue ter esse contato, fazer sua sugestão ou denúncia. (G.E.1).

Assim, é trazido o papel das ouvidorias públicas, que, conforme expresso no 'Guia de orientações para gestão de ouvidorias', é o de intermediar as relações entre os cidadãos que as demandam e os órgãos ou entidades aos quais pertencem, promovendo a qualidade da comunicação entre eles e a formação de laços de confiança e colaboração mútua (BRASIL, 2013B).

Esse pressuposto pode ser identificado na fala dos gestores entrevistados, que entendem a ouvidoria como uma ferramenta que favorece a participação da comunidade na gestão do SUS, na medida em que permite ao usuário expressar sua opinião, sugestão ou mesmo indicar quais necessidades os serviços de saúde prestados não atendem.
Então, o papel da ouvidoria, ele vai servir mesmo como uma participação social, porque a gente também tem outras formas de participação e que a gente estimula, como os Conselhos populares, que nós temos em todas as regionais da cidade. A gente tem Conselhos populares de saúde. (G.E.2).

A ouvidoria permite, na visão dos gestores, realizar uma avaliação da conduta do sistema de saúde, o que possibilita à gestão repensar suas estratégias e redefinir os caminhos a serem percorridos: "Agora, uma ouvidoria, essa é a minha visão, ela só funciona se a gente der resposta às sociedades pelas demandas..." (G.E.1).

Durante a caracterização do discurso do gestor a respeito do papel da ouvidoria, é possível perceber, também, que eles entendem a ouvidoria como mecanismo de participação social. Embora o gestor expresse em seu discurso a importância da ouvidoria como mecanismo de participação da comunidade, o mesmo volta-se, ainda, para o papel fiscalizador das ouvidorias.

É importante mencionar que apenas um dos gestores entrevistados reconheceu que, 
para que a ouvidoria se legitime como mais um instrumento de participação, é preciso que ela atenda e/ou dê resposta ao usuário demandante, sendo essa premissa fundamental à ouvidoria em termos de atribuição de confiabilidade e legitimação à mesma.

A maior parte dos discursos identifica a ouvidoria como estratégia para ouvir as reclamações da comunidade sobre os serviços ofertados e como ferramenta de gestão, conforme é possível identificar no item a seguir.

\section{A ouvidoria como ferramenta de gestão}

Para os gestores entrevistados, além de garantir a participação do cidadão na construção da política pública de saúde, a ouvidoria é considerada um instrumento de gestão, um espaço que garante avaliação das ações e serviços prestados à população.

Uma das questões feitas aos gestores foi a respeito de como as informações obtidas pela ouvidoria do SUS teriam auxiliado em sua gestão. Neste sentido, as respostas apontaram algumas das questões mais comuns que surgem para a ouvidoria, como as denúncias relacionadas à gestão de pessoas.

Demais, em todos os sentidos, em questão de Médico, em questão de Dentista, de Técnico de Enfermagem, dos trabalhadores da saúde, técnicos de vacina, a gente também, de vez em quando, tem problema dos ACS. Sempre precisamos.. Já fizemos até remanejamento dentro da microárea de acesso, que não está dando certo. Em uma área, a gente faz o remanejamento para que o serviço melhore, tudo baseado nas denúncias feitas à ouvidoria. (G.E.2).

Em muitos casos, as reclamações voltam-se aos ACS que não fizeram a visita ou ao atendente que não sabe fornecer a informação solicitada, à falta de médicos, à ausência de medicamentos básicos e até mesmo a um grande esquema de corrupção nas filas de marcação de consultas e procedimentos de alto custo.
[...] reclamação sobre os Agentes Comunitários de Saúde sobre a visita. Então, todos os meses, a gente tem reunião com eles e organiza toda a agenda de visitas. Como somos de um município muito pequeno, é mais fácil de receber esse retorno da comunidade. (G.E.3).

[...] a demora de atendimento em uma determinada situação. Então, às vezes, a gente descobre que a demora se dá porque esqueceram de colocar disponível um estetoscópio. (G.E.4).

[...] foi através disso que eu consegui detectar fura-fila aqui, por exemplo, através de situações, pela ouvidoria, de coisinhas que chegaram, a gente começou a entender como estava funcionando a central de marcação nossa, isso associado à ouvidoria itinerante que a gente fez - eu também ouvi lá isso, associado a conversas com outras pessoas aqui. A gente detectou que tinha influências externas à Secretaria de Saúde, sempre trazendo nomes para serem agendados, antecipados, na central de marcação. (G.E.7).

Silva, Pedroso e Zucchi (2014), a partir do estudo de caso de uma ouvidoria municipal de saúde, no que se refere ao olhar de usuários e conselheiros de saúde, também trazem aspectos relacionados ao papel da ouvidoria na gestão do SUS. Na visão dos usuários, a ouvidoria teria como principais funções auxiliar na solução de problemas de saúde, além de ouvir e esclarecer sobre o funcionamento do SUS. Já os conselheiros deram destaque ao importante papel da ouvidoria na mediação entre conselho, gestão e população, enfatizando a informação como instrumento de poder e de acesso aos direitos dos usuários.

A ouvidoria, em si, recolhe as denúncias, reclamações, sugestões ou elogios e encaminha às instâncias responsáveis. Apesar de não ter sido explorado na pesquisa o aspecto da ouvidoria e seu poder de decisão na gestão pública, nesse sentido, a literatura mostra 
que não é concedido à ouvidoria nenhum poder de decisão na gestão. Ela faz apenas recomendações à gestão.

Lyra (2004) explica que o êxito das experiências participativas no Brasil está associado à necessidade da população de instrumentos de gestão que garantam a transparência do Estado, diminuindo a corrupção e o desperdício dos recursos públicos e possibilitando aumento da moralidade e eficiência da administração pública. Baseados nessa possibilidade de ampliar os canais de participação cidadã e, ainda, de favorecer a gestão é que, segundo o autor, foi possível o avanço da implementação das ouvidorias por todo o País.

De acordo com a visão dos gestores, a ouvidoria do SUS é ferramenta de gestão à medida que publiciza os problemas de execução da política de saúde em dada localidade, a partir do olhar e da necessidade do usuário, e facilita a observação dos limites e das dificuldades de alcance de uma intervenção, quando verifica o grau de aceitação, realizando as pesquisas de opinião e através de demandas, sugestões, denúncias ou elogios que a ouvidoria do SUS acolhe.

Elas ajudam a mostrar os teus pontos frágeis. Essa fragilidade que você tem e que você pode ir consertando e tendo o conhecimento do que está ocorrendo. (G.E.4).

Esse cenário possibilita, segundo os gestores, a avaliação e o monitoramento das ações e dos serviços prestados à população, entendendo que o processo de avaliação tem caráter permanente e funciona a partir da perspectiva do usuário do SUS, o que contribui para o aperfeiçoamento gradual e constante dos serviços públicos de saúde (BRASIL, 2009).

[...] fazendo escuta qualificada de problemas ou de possíveis problemas, passou a ser disparador de processos para atuar sobre problemas identificados. A ouvidoria foi e deve ser ferramenta de gestão importante. (G.E.5).
A ouvidoria do SUS nos municípios exerce um papel de grande importância para a garantia da cidadania e, muito evidentemente, para a gestão dos serviços de saúde, que se propõe ser ética, democrática e participativa.

[...] a gestão da ética tem por objetivo estabelecer padrões éticos de conduta nas organizações de forma a não deixar dúvidas quanto à conduta esperada em situações específicas. Transita em um eixo bem definido, onde se encontram valores, regras de conduta e administração. (SOARES, 2002, P. 9-10).

A partir dos achados da pesquisa, foi possível perceber que os entrevistados reconhecem, sim, a ouvidoria como ferramenta de gestão, sobretudo sua contribuição para a construção de um sistema de saúde que preze pela ética em sua prática de gestão. Tal aspecto denota avanços no objetivo de contribuir para uma gestão pública de qualidade e que valorize os mecanismos que favorecem a participação da comunidade, ainda que individualmente, na construção da política de saúde.

Os gestores de saúde deverão utilizar os dados dos serviços de ouvidoria do SUS como ferramenta para o estabelecimento de estratégias da melhoria das ações e dos serviços de saúde prestados pelo SUS. (BRASIL, 2014A).

Nesse aspecto, os gestores entrevistados estão em concordância com o que determina a Portaria do Ministério da Saúde $n^{0}$ 2.416, de 7 de novembro de 2014, que dispõe sobre as diretrizes para a organização e o funcionamento dos serviços de ouvidoria do SUS e suas atribuições (BRASIL, 2014A).

[...] uma vez por mês, a cada final de mês, a gente sai recolhendo os nossos questionários das urnas e a gente faz um levantamento de cada PSF [Programa Saúde da Família], o que está dando certo, o que não está dando certo. Reúne com a equipe, mostra o que realmente a população está reclamando, se foi de um atendimento, vamos 
dizer, de um profissional. A gente tenta conversar com ele a primeira vez, a segunda, a terceira... Não deu certo, a gente tem que mudar de setor, porque alguma coisa não está dando certo. (G.E.6).

A ouvidoria se consolida como ferramenta de gestão à medida que as informações recolhidas, identificadas e tipificadas (grau de relevância, urgência e tipo de demanda) pela ouvidoria são repassadas ao gestor, e este, sensível à necessidade de ouvir o usuário do serviço, dispõe-se, junto à sua equipe, a analisar e dar seguimento à demanda. Conforme relata o G.E.6, é possível realizar uma avaliação da condução dos processos de gestão do SUS e, com isso, possibilitar a resposta ao usuário, seja fornecendo a informação que ele busca ou mesmo reorganizando os serviços que não atendem às reais demandas da população.

\section{Considerações finais}

São atribuições principais de uma ouvidoria do SUS: sugerir a mudança na gestão, a avaliação e a reavaliação dos serviços prestados à população, favorecer o acesso do usuário à administração pública e promover a democracia participativa no SUS.

A pesquisa demonstrou que os gestores entrevistados têm a ouvidoria em saúde como um mecanismo de participação da comunidade, fato que nos permite concluir que, na percepção dos gestores entrevistados, a ouvidoria é uma instância promotora de cidadania. Neste sentido, compreende-se participação da comunidade também como a participação individual do usuário, sendo ele representante de sua própria fala.

Conceber a ouvidoria como um mecanismo de participação da comunidade é fazer dela um instrumento de gestão. Levando em conta a administração burocrática do Estado, é um ato de ousadia, coragem, vontade política e, sobretudo, trata-se da expressão de valores éticos firmes e comprometidos com a gestão do SUS.

A ouvidoria apresentada pelo gestor municipal de saúde aqui neste trabalho, por mais que seja mecanismo de participação da comunidade e instrumento de gestão, ainda se apresenta de maneira tímida ao usuário, sendo necessário ampliar os canais de acesso às ouvidorias para possibilitar que mais usuários tenham a possibilidade de contribuir para a gestão dos serviços de saúde.

Outro desafio para a ouvidoria consiste na efetivação de uma ouvidoria ativa que vá em busca do usuário para identificar suas necessidades, identificar no território quais são os problemas de implementação da política de saúde, para, com isso, favorecer o acesso do usuário aos serviços da ouvidoria, aquele ‘olho no olho', momento em que o ouvidor tem contato direto com o usuário e pode realizar a escuta em uma perspectiva de humanização. Essa observação se faz necessária, uma vez que apenas 2, das 10 ouvidorias visitadas, realizavam alguma estratégia de ouvidoria ativa. As demais ainda estão restritas às funções mais tradicionais de uma ouvidoria receptiva.

É preciso ressaltar que o estudo foi realizado considerando-se os limites observados em campo, como a ausência de comparação dos discursos dos gestores com a fala da comunidade, bem como das ouvidorias dos municípios a respeito do objeto explicitado: ouvidoria como mecanismo de participação e ferramenta de gestão.

Além disso, ao longo do trabalho, foi possível observar a escassez de literatura que trate sobre a ouvidoria como ferramenta de gestão na prática. Faltam informações e existem poucas metodologias que avaliem a efetividade das ações da ouvidoria do SUS.

Propõe-se, assim, que este trabalho possa ter continuidade, para que seja possível avançar nas discussões do uso da ouvidoria como ferramenta de gestão, a fim de identificar como, na prática, isso ocorre, propondo o compartilhamento de estratégias de qualificação do trabalho das ouvidorias. 


\section{Referências}

BRASIL. Constituição da República Federativa do Brasil de 1988. Brasília, DF: Senado Federal, 1988. Disponível em: <http://www.senado.gov.br/atividade/const/ con1988/CON1988_05.10.1988/CON1988.asp>. Acesso em: 11 ago. 2016.

Controladoria-Geral da União. Ouvidoria-Geral da União. Orientações para implantação da lei de acesso à informação nas Ouvidorias Públicas: rumo ao sistema participativo. 5 ed. Brasília, DF: Controladoria-Geral da União, 2012.

Ministério da Saúde. Gabinete do Ministro. Portaria $\mathrm{n}^{\circ}$ 2.416, de 7 de novembro de 2014. Estabelece diretrizes para a organização e funcionamento dos serviços de ouvidoria do Sistema Único de Saúde (SUS) e suas atribuições. Diário Oficial [da] União. Brasília, DF, 7 nov. 2014a. Disponível em: <http://bvsms.saude. gov.br/bvs/saudelegis/gm/2014/prt2416_07_11_2014. html>. Acesso em: 11 ago. 2016.

Ministério da Saúde. Secretaria de Gestão Estratégica e Participativa. Orientações básicas para implantação de ouvidorias do SUS. 2013a. Disponível em: <http://www.cgu.gov.br/assuntos/ouvidoria/ produtos-e-servicos/consulta-publica/arquivos/ produto_5_gestao_de_ouvidorias.pdf $>$. Acesso em: 10 jun. 2015.

Ministério da Saúde. Secretaria de Gestão

Estratégica e Participativa. Política Nacional de Gestão Estratégica e Participativa no SUS: ParticipaSUS. 2 ed. Brasília, DF: Ministério da Saúde, 2009.

Ministério da Saúde. Secretaria de Gestão Estratégica e Participativa. Departamento de Ouvidoria-Geral do SUS. Manual das Ouvidorias do SUS. Brasília, DF: Ministério da Saúde, 2014b. Disponível em: <http://bvsms.saude.gov.br/bvs/ publicacoes/manual_ouvidoria_sus.pdf $>$. Acesso em: 11 ago. 2016.

Ministério da Saúde. Secretaria de Gestão

Estratégica e Participativa. Departamento de Ouvidoria-Geral do SUS. Ouvidoria Ativa do SUS: ampliando a escuta e o acesso à informação do cidadão. Brasília, DF: Ministério da Saúde, 2014c. Disponível em: <http://u.saude.gov.br/images/pdf/2014/maio/14/ compendio-ouvidoria-ativa.pdf $>$. Acesso em: 11 ago. 2016.

Ministério do Planejamento, Orçamento e Gestão. Ouvidoria-Geral da União. Guia de orientações para Gestão de Ouvidorias. 2013b. Disponível em: $<$ http://www.cgu.gov.br/assuntos/ouvidoria/produtose-servicos/consulta-publica/arquivos/produto_5_ gestao_de_ouvidorias.pdf $>$. Acesso em: 11 ago. 2016.

Presidência da República. Casa Civil. Subchefia para Assuntos Jurídicos. Decreto $n^{\circ} 4.726$, de 9 de junho de 2003. Aprova a Estrutura Regimental e o Quadro Demonstrativo dos Cargos em Comissão e das Funções Gratificadas do Ministério da Saúde, e dá outras providências. Diário Oficial [da] União. Brasília, DF, 9 jun. 2003. Disponível em: <http://www.planalto. gov.br/ccivil_03/decreto/2003/D4726.htm>. Acesso em: 11 ago. 2016.

Presidência da República. Casa Civil. Subchefia para Assuntos Jurídicos. Lei no 8.142, de 28 de dezembro de 1990. Dispõe sobre a participação da comunidade na gestão do Sistema Único de Saúde (SUS) e sobre as transferências intergovernamentais de recursos financeiros na área da saúde e dá outras providências. Diário Oficial [da] União. Brasília, DF, 28 dez. 1990. Disponível em: <http://www.planalto.gov.br/ ccivil_03/leis/L8142.htm>. Acesso em: 11 ago. 2016.

CARVALHO, D. B.; SANTANA, J. M.; SANTANA, V.

M. Humanização e controle social: o psicólogo como ouvidor hospitalar. Psicol. cienc. prof., Brasília, DF, v. 29, n. 1, p. 172-183, 2009. Disponível em: <http://www. scielo.br/scielo.php?script=sci_arttext\&pid=S1414$98932009000100014 \& \operatorname{lng}=$ pt $\& n r m=$ iso $>$. Acesso em: 21 jul. 2015.

LYRA, R. P. (Org.). Autônomas $x$ Obedientes: a Ouvidoria Pública em debate. João Pessoa: UFPB, 2004. 
OMBUDSMAN SASKATCHEWAN. The History

of the Ombudsman. Disponível em: <https://

www.ombudsman.sk.ca/info/the-history-of-the-

ombudsman>. Acesso em: 9 jun. 2015.

ORLANDI, E. P. Análise de Discurso: princípios e procedimentos. Campinas: Pontes, 1999.

PEIXOTO, S. F.; MARSIGLIA, R. M. G.; MORRONE, L. C. Atribuições de uma ouvidoria: opinião de usuários e funcionários. Saúde Soc., São Paulo, v. 22, n. 3, p. 785794, set. 2013. Disponível em: <http://www.scielo.br/ scielo.php?script=sci_arttext $\&$ pid=S010429020130003 00012\&lng=en\&nrm=iso>. Acesso em: 28 jun. 2016.

PROGRAMA DAS NAÇÕES UNIDAS PARA

O DESENVOLVIMENTO (PNUD). Atlas do

Desenvolvimento Humano. Disponível em:

$<$ http://www.pnud.org.br/IDH/Default.

aspx?indiceAccordion=1\&li=li_AtlasMunicipios>.

Acesso em: 10 jun. 2015.

ROLIM, L. B.; CRUZ, R. S. B. L. C.; SAMPAIO, K. J. A. J.

Participação popular e o controle social como diretriz do SUS: uma revisão narrativa. Saúde debate, Rio de Janeiro, v. 37, n. 96, p. 139-147, mar. 2013. Disponível em: $<$ http://www.scielo.br/scielo.php?script=sci_arttext\&p $\mathrm{id}=\mathrm{S} 0103042013000100016 \& \operatorname{lng}=\mathrm{pt} \& \mathrm{nrm}=\mathrm{iso}>$. Acesso em: 28 jun. 2016.

SILVA, R. C. C.; PEDROSO, M. C.; ZUCCHI, P. Ouvidorias públicas de saúde: estudo de caso em ouvidoria municipal de saúde. Rev. Saúde Pública, São Paulo, v. 48, n. 1, p. 134-141, fev. 2014. Disponível em: <http://www.scielo.br/scielo.php?script=sci arttext\&pid=S0034-89102014000100134\&lng=pt\&nrm =iso>. Acesso em: 21 jul. 2015.

SOARES, M. S. B. Ética como instrumento de gestão. In: ENCONTRO DE REPRESENTANTES SETORIAIS DA COMISSÃO DE ÉTICA PÚBLICA, 2, 2002, Brasília, DF. Anais... Brasília, DF: ESAF, 2002.

Recebido para publicação em novembro de 2015

Versão final em agosto de 2016

Conflito de interesses: inexistente

Suporte financeiro: não houve 